\title{
Role of Structural Defects in the Adsorption and Separation of C3 Hydrocarbons in Zr-Fumarate-MOF (MOF-801)
}

\author{
Paul Iacomi, ${ }^{\dagger, \nabla} \nabla_{\odot}$ Filip Formalik, ${ }^{\dagger, \S, \nabla}$ Joao Marreiros, ${ }^{\| \oplus}{ }^{\oplus}$ Jin Shang, ${ }^{\perp \odot}$ Justyna Rogacka,
}

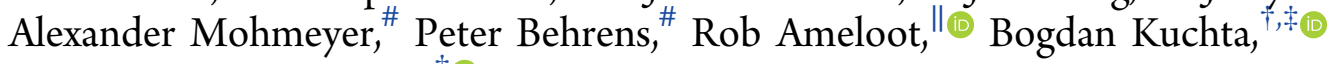
and Philip L. Llewellyn* ${ }^{\dagger} \dagger$

${ }^{\dagger}$ Aix-Marseille University, CNRS, MADIREL (UMR 7246), 13013 Marseille, France

${ }^{\ddagger}$ Bioprocess and Biomedical Engineering Group, Faculty of Chemistry, Wroclaw University of Science and Technology, Wybrzeże Wyspiańskiego 27, 50-370, Wroclaw, Poland

${ }^{\S}$ Department of Theoretical Physics, Faculty of Fundamental Problems of Technology, Wroclaw University of Science and

Technology, Wybrzeże Wyspiańskiego 27, 50-370, Wroclaw, Poland

${ }$ Centre for Surface Chemistry and Catalysis, KU Leuven, Celestijnenlaan 200F, P.O. Box 2461, 3001 Leuven, Belgium

${ }^{\perp}$ School of Energy and Environment, City University of Hong Kong, Tat Chee Avenue, Kowloon, Hong Kong SAR, People's Republic of China

${ }^{\#}$ Institute for Inorganic Chemistry, Leibniz Universität Hannover, Callinstr. 9, 30167 Hannover, Germany

Supporting Information

\begin{abstract}
An effective separation of propylene/propane mixtures is one of the most important processes in the petrochemical industry. Incidentally, this separation is challenging due to the extensive similarities between both gases in terms of physicochemical properties such as, but not only limited to, boiling point, kinetic diameter, and molecular weight. A drive to switch to energy efficient processes, like adsorption or membrane separation, has highlighted several microporous metal organic frameworks as promising materials. In this work, we present a combined numerical and experimental investigation on propane and propylene adsorption in $\mathrm{Zr}$-fumarate-MOF (also known as

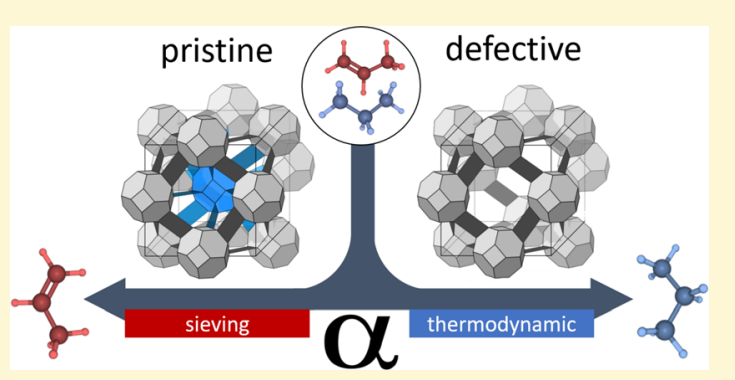
MOF-801), a small pore isoreticular analogue of UiO-66. Here, we demonstrate how the presence of structural defects can completely change the sorptive properties and separation performance of the $\mathrm{Zr}$-fumarate-MOF, with the loss of sieving effects and a reversal of selectivity toward propane, as well as enhanced capacity and diffusion rates for C3-sized hydrocarbons. Extensive GCMC simulations performed on mixed defective supercells show that a ratio of missing-cluster defects of around 1/ 8 can best account for the experimental results. Furthermore, analysis of low-frequency phonon spectra is used to explain gaseous diffusion in the original pristine material. Finally, the thermodynamic preference for propane over propylene is confirmed through column breakthrough experiments, suggesting the potential applicability of the $\mathrm{Zr}$-fumarate-MOF in this challenging separation.
\end{abstract}

\section{INTRODUCTION}

One of the most challenging large-scale separations is that of propane/propylene mixtures, a common byproduct in conventional olefin or fluid catalytic cracking plants, or as the main output of targeted propylene synthesis, such as propane dehydrogenation. With the abundance of natural propane from shale gas in recent years and the increasing global demand for propylene, the latter is becoming more industrially attractive. ${ }^{1}$ The current standard practice for this separation is cryogenic distillation, an energetically intensive process, requiring compression of the gas mixture and low temperatures. ${ }^{2}$ Furthermore, owing to the similar physical properties of propane and propylene (boiling points, vapor pressure, etc.), commonly employed distillation columns require a large number of stages and reflux ratios, increasing the overall energy cost. Consequently, the development of alternative separation avenues is crucial for reducing the production cost of this industry relevant olefin.

A promising alternative can be found in the use of porous materials to perform the separation through adsorptive means, either based on the thermodynamics or kinetics of physisorption or otherwise through molecular sieving. ${ }^{3}$ The shift to such methods is particularly attractive due to the relatively low energy cost of adsorbed phase recovery when compared to current practices. ${ }^{4}$ Performance of said processes greatly depends on the properties of the adsorbent materials, as 
well as the capability for proper and controlled structuring of these sorbents into beads, columns, or membranes. To date, considerable studies have been reported on the matter, with particular focus on the use of polymers, ${ }^{5-7}$ carbonaceous materials, ${ }^{8-10}$ or zeolites ${ }^{3,11-16}$ as the porous media.

Thermodynamic separation is achieved through equilibrium concentration differences in the adsorbed phase, caused by a difference in the strength of attractive interactions between components in the mixture and the adsorbent surface. Propylene selectivity in such a process is usually due to interactions involving the $\pi$ electrons of the double bond. ${ }^{17,18}$ Instead, when specific guest-host interactions are absent, a slight propane selectivity can be observed, ${ }^{8,19}$ attributed to larger intermolecular interactions of the saturated molecule. ${ }^{10}$ Kinetic separations rely on differences in gaseous diffusion rates in a pore network and are necessarily transient or flowbased processes, used in columns or membranes. Diffusion can be dominated either by size-controlled diffusion, where the smaller component is generally selected for retention, or by surface diffusion after adsorption, in which the stronger adsorbed component is preferably retained. ${ }^{20}$ The kinetic diameter difference between propylene $(0.40 \mathrm{~nm})$ and propane $(0.43 \mathrm{~nm})^{21}$ is minimal, requiring a material with a welldefined pore entrance and very narrow pore size distribution if kinetic separation is desired. Such a process can be encountered in small window DDR zeolites ${ }^{22-24}$ where faster propylene diffusion leads to its preferential adsorption. Finally, molecular sieving occurs when the pore apertures in the adsorbent material are simply too small for one mixture component to enter the pore.

Metal-organic frameworks (MOFs) have been an intensely studied area in materials science, owing to their potential as highly tunable materials. Indeed, with judicious design, the skilled chemist can manipulate pore shape, window size, surface interactions, and even introduce stimuli-responsive material changes through decoration of a particular topological net. These materials offer promise in areas of gas adsorption such as storage and separation, where conventional adsorbents fail to achieve the desired performance, and where their unique characteristics (tunability, defects, compliance, etc.) can be leveraged for highly specific applications. In the area of propane/propylene separations, MOFs have been the focus of several avenues of study. Frameworks with open metal sites, such as copper paddlewheels, ${ }^{25,26}$ iron trimers, ${ }^{27}$ or the closely related family of hexacyanometallates, ${ }^{28}$ have been shown to preferentially adsorb propylene due to specific interactions with these sites. Alternatively, the isoreticular chemistry approach can be employed to obtain pore window sizes in the exact range required for kinetic separation ${ }^{29}$ or molecular sieving. ${ }^{30}$ Furthermore, MOF zeolite analogues such as ZIF$8^{31,32}$ and ZIF-7 ${ }^{33,34}$ have shown promise for parrafin/olefin separations, due to the disparity in diffusivities introduced by the small cage entrances and gate opening effects. ${ }^{35}$

$\mathrm{Zr}$-fumarate-MOF, ${ }^{36}$ later renamed to MOF- $801,{ }^{37}$ is a fumaric acid analogue of the topical UiO-66(Zr) framework. It shares the same face-centered cubic (fcc) topology, with inorganic clusters interconnected by a smaller, nonlinear dicarboxylate linker, leading to a lowering of symmetry and slight tilting of the $\left[\mathrm{Zr}_{6}\left(\mu_{3}-\mathrm{O}\right)_{4}\left(\mu_{3}-\mathrm{OH}\right)_{4}\right]^{12+}$ clusters, as depicted in Figure 1. Synthesis can only take place under modulation/coordination conditions, using considerable amounts of competing monotopic acids as the modulator, resulting in higher crystallinity and yield of the material.
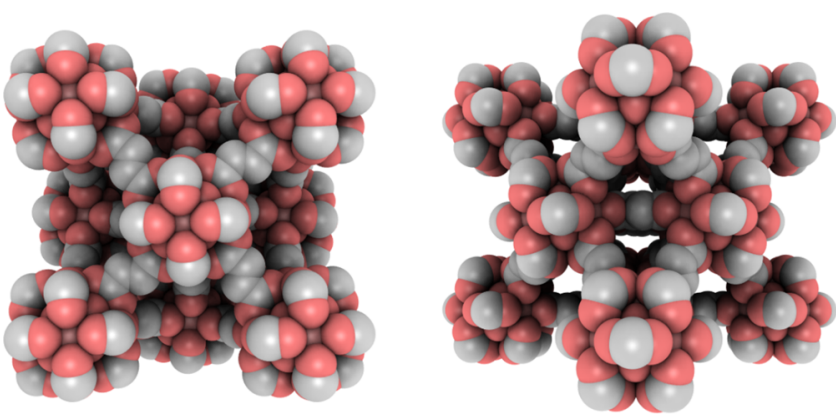

Figure 1. Structure of Zr-fum-MOF: front (left) and side (right) views (generated by iRASPA software ${ }^{46}$ ).

Indeed, when not using this approach, the resulting material is nearly amorphous. ${ }^{38} \mathrm{Zr}$-fumarate-MOF has recently been the subject of scientific interest due to its high water stability, ${ }^{39}$ as well as its potential for green synthesis ${ }^{40}$ and facile shaping through direct monolith formation by a gel approach. ${ }^{41}$ The material has a remarkably steep water adsorption isotherm at low relative pressure, ${ }^{37}$ which led to its possible application as a water scavenger membrane $e^{42}$ or in a water harvesting device which would capture water from air in low relative humidity environments. ${ }^{43}$ This low pressure condensation step for water has highlighted the contribution of defects in shifting the adsorption isotherm, an effect arising from cooperative interactions and initial clustering of water molecules at defect sites. ${ }^{44}$ The window diameter of the $\mathrm{Zr}$-fumarate-MOF is in the same length scale as $\mathrm{C} 3$ hydrocarbons, an aperture size which has been shown in studies on similar fcu MOFs ${ }^{30}$ to be suitable for kinetic or exclusion-driven separations. For these reasons, this MOF was previously highlighted as a prime candidate for propane/propylene separations. ${ }^{45}$ However, the presence of structural defects may have a large impact on the adsorption of these gases.

In the following, we present a combined computational and experimental approach describing the adsorption behavior of saturated and monounsaturated $\mathrm{C} 3$ hydrocarbons in a defectrich $\mathrm{Zr}$-fum-MOF system. We evaluate the contribution of defects in the synthesized material and demonstrate their crucial impact on the diffusion of the gaseous phase in the crystalline MOF. Grand canonical Monte Carlo (GCMC) adsorption simulations are performed on several structural models containing a range of defects, of varying nature and concentration/distribution, to reproduce experimental isotherms. We also perform calculations of phonon spectra, revealing the potential for pore window deformations, which can explain previously observed diffusion of gases in the pristine version of the material. ${ }^{45}$ The enthalpies of adsorption of propane and propylene are both calculated through the Widom insertion method and measured in situ through microcalorimetry, with propane adsorption shown to be more energetically favorable. This can be correlated with a higher selectivity for propane over propylene in mixture coadsorption experiments, predicted through ideal adsorbed solution theory (IAST) and in silico simulations, and further investigated by column breakthrough experiments. As opposed to a perfect material, defects are shown to drastically increase the uptake of all probes and to increase the mobility probability through the newly generated voids (missing structural elements $=$ more free space $=$ less $\mathrm{physical} /$ steric impediment). We then discuss the unexpected thermodynamic 
selectivity in the defective material which runs opposite to the sieving effect which has been observed in a pristine structure. ${ }^{45}$

\section{RESULTS AND DISCUSSION}

Sample Synthesis and Preliminary Characterization. The $\mathrm{Zr}$-fumarate-MOF sample was synthesized following the previously reported method, ${ }^{47}$ where a large excess of formic acid (100 equiv) is added together with the MOF precursors in water as the reaction medium, to obtain a white precipitate of $\mathrm{Zr}$-fum-MOF crystals. For further characterization, the precipitate was Soxhlet-extracted with ethanol and afterward dried under reduced pressure. The phase purity of the resulting powder was confirmed by comparing experimental powder Xray diffraction (PXRD) patterns to those simulated from structural data (Figure S2). Scanning electron microscopy (SEM) of the MOF revealed well-defined octahedral crystals with an average diameter of 100-200 nm (Figure S1).

Nitrogen physisorption recorded at $77 \mathrm{~K}$ was used to determine a Brunauer-Emmett-Teller (BET) specific surface area of $963 \mathrm{~m}^{2} / \mathrm{g}$ and a t-plot calculated micropore volume of $0.38 \mathrm{~cm}^{3} / \mathrm{g}$. The pore size distribution calculated from this isotherm shows two peaks, corresponding to the tetrahedral and octahedral cages, respectively (Figure S5). However, the distribution also indicates that pores larger than the crystal structure would suggest (in the $1-2 \mathrm{~nm}$ range) are present, accounting for a substantial increase in volumetric uptake and strongly supporting the existence of structural defects. The thermogravimetric curve (Figure S3) recorded in an air atmosphere shows a pronounced mass loss below $400 \mathrm{~K}$, as the large amount of water and other guests in the structure are removed. Two further steps are observed: one at $600 \mathrm{~K}$, corresponding to the degradation and subsequent oxidation of the organic linker, with a further step around $830 \mathrm{~K}$ which has been previously associated with the decomposition of zirconium-coordinated carbonate groups. ${ }^{36,39}$ We further confirm the similarity of the synthesized material with existing literature by recording water adsorption at $298 \mathrm{~K}$. The resulting isotherm (Figure S6) shows a pronounced pore condensation step at $\sim 0.1 p / p^{0}$ and near-complete reversibility in the desorption branch, in accordance with previous results. ${ }^{37,44}$

Adsorption Microcalorimetry Screening. To screen the Zr-fumarate-MOF for potentially interesting adsorption properties, the isotherms of nine probe gases $\left(\mathrm{Ar}, \mathrm{N}_{2}, \mathrm{O}_{2}\right.$, $\mathrm{CO}, \mathrm{CH}_{4}, \mathrm{CO}_{2}, \mathrm{C}_{2} \mathrm{H}_{6}, \mathrm{C}_{3} \mathrm{H}_{8}, \mathrm{C}_{3} \mathrm{H}_{6}$ ) were recorded in a microcalorimeter, allowing for a measurement of the differential enthalpy of adsorption $\left(\Delta_{\mathrm{ads}} h\right)$ for each isotherm point. The entire data set is available in Figure S8. The material shows relatively flat, gently decreasing enthalpy curves for $\mathrm{Ar}$, $\mathrm{N}_{2}, \mathrm{O}_{2}, \mathrm{CO}$, and $\mathrm{CH}_{4}$, corresponding to adsorption on homogeneous sites. In contrast, enthalpy curves for $\mathrm{CO}_{2}$, $\mathrm{C}_{2} \mathrm{H}_{6}, \mathrm{C}_{3} \mathrm{H}_{8}$, and $\mathrm{C}_{3} \mathrm{H}_{6}$ show a sharp decrease in $\Delta_{\text {ads }} h$, to a lower plateau, suggesting an initial preferential interaction followed by weaker interactions with the pore surface. These four probes are the only ones for which the isotherm plateau is reached in the pressure range studied, corresponding to complete pore filling. More interestingly, the enthalpy of adsorption of propane in the low-loading region $(<2 \mathrm{mmol}$ $\mathrm{g}^{-1}$ ) is found to be higher on average than that of propylene. If the enthalpy curve is extrapolated to obtain the enthalpy of adsorption at zero loading $\left(\Delta_{\text {ads }} h_{0}\right)$, values of $\sim 38 \mathrm{~kJ} \mathrm{~mol}^{-1}$ and $\sim 44 \mathrm{~kJ} \mathrm{~mol}^{-1}$ are obtained for propylene and propane, respectively, suggesting a stronger guest-host interaction with the saturated molecule. This result is unexpected, as propylene is commonly thermodynamically preferentially adsorbed in most previously studied adsorbent materials, owing to increased interactions between the double bond and framework features such as open metal sites. In order to put this difference into perspective, $\Delta_{\text {ads }} h_{0}$ has been calculated for the entire series of probes, together with the initial Henry constant $\left(H_{K, 0}\right)$, another measure of structure-adsorbate interactions, and plotted versus the specific polarizability of each probe molecule (Figure 2). Probes which interact with the framework
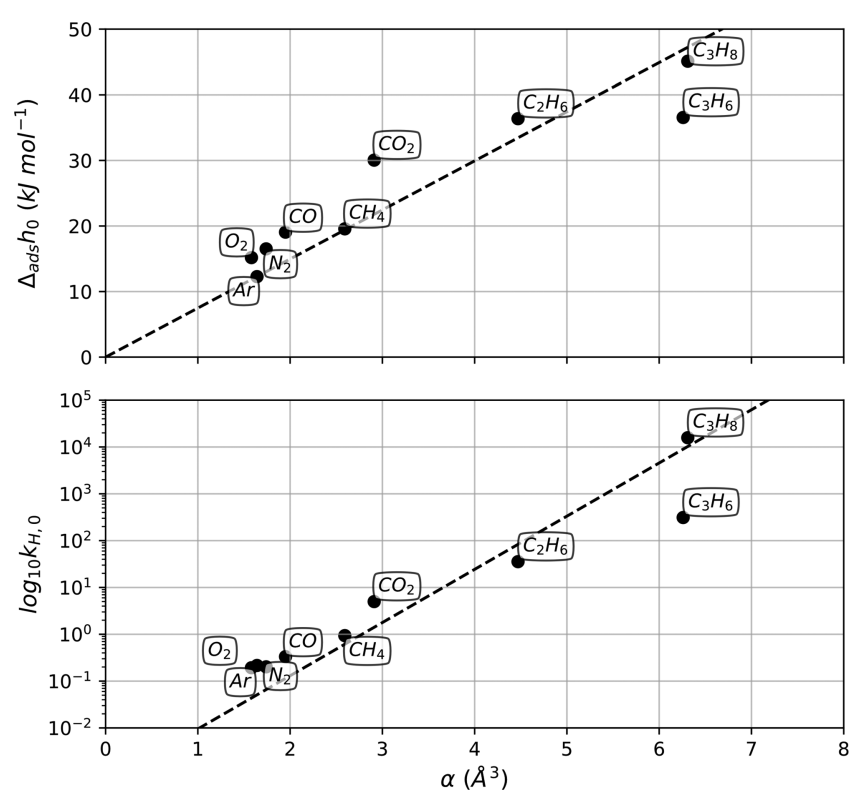

Figure 2. Zero-loading differential enthalpy of adsorption (top) and logarithm of initial Henry constant (bottom) plotted against the polarizability of each specific gas molecule. Dotted lines are leastsquares fits to the $y$ axis values for $\mathrm{C} 1-\mathrm{C} 3$ saturated hydrocarbons.

through nonspecific interactions, such as noble gases and unsaturated hydrocarbons, are expected to exhibit a linear evolution of $\Delta_{\mathrm{ads}} h_{0}$ and $H_{K, 0}$ with respect to their polarizability. In such a case, the slope of the resulting correlation line is representative of the field gradient encountered in the pore where adsorption takes place. We can observe that both values for propylene fall below the predicted linear relationship. It could be argued that the slow uptake kinetics of the gas at low loading may influence the recorded heat flow. However, when observing the time-resolved uptake for the $0-0.05$ bar pressure range (Figure S9), the adsorption kinetics for both gases do not differ significantly on this material.

C3 Adsorption in Pristine Zr-Fumarate-MOF. To focus on the unusual C3 hydrocarbon measurements, propane and propylene single component adsorption isotherms were recorded separately (Figure 3 ). The isotherms show a larger amount of propylene adsorbed at saturation, as expected due to the higher packing efficiency of propylene and its consequently higher fluid phase density. However, a crossover is observed around 0.1 bar, with propane capacities overtaking its unsaturated analogue below this pressure. To understand the microscopic mechanism of the single component adsorption of propane and propylene, we turn to in silico methods. Using Monte Carlo simulations within the grand canonical ensemble (GCMC methods), we can simulate gas 


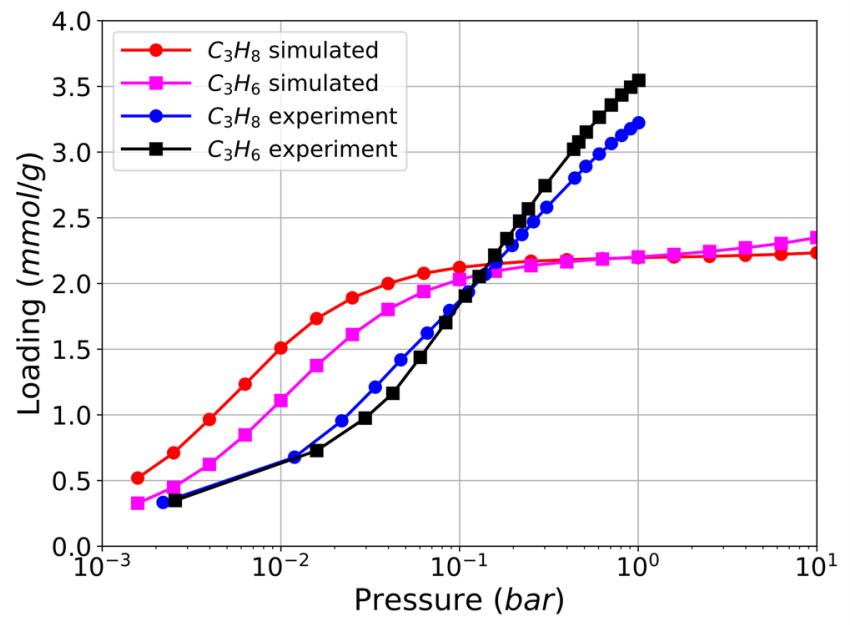

Figure 3. Experimentally measured isotherms on the $\mathrm{Zr}$-fumarateMOF sample (blue and black) compared to simulated adsorption in the ideal structure of $\mathrm{Zr}$-fumarate-MOF (red and pink) of propane (round markers) and propylene. Isotherm confidence ranges are below $2 \%$ and are not shown on the graph.

adsorption and model isotherms in a MOF structure, real or hypothetical.

The adsorption isotherms obtained for the ideal (nondefective) structure significantly differ from the experimental results (overlaid in Figure 3). The uptake calculated in the low- pressure region exceeds the experimental values, which can be attributed either to (i) inaccuracies in the force field definition, especially of the $\varepsilon$ value, responsible for the strength of the interactions between molecules, as well as host-guest interactions (through Lorentz-Berthelot mixing rules), or to (ii) the existence of stronger adsorption sites which do not exist in the experimental sample. On the other hand, modeled results underestimate uptake for higher pressures $(>0.1$ bar) where the experimental uptake substantially exceeds the theoretical values by almost $75 \%$. As before, the divergence can be attributed to the definition of the size of the molecules in the force field ( $\sigma$ parameter) or further interpreted as the existence of pores of different diameters in ideal and real structures. In this study, we made use of the force field developed by the group of Sofia Calero ${ }^{48}$ to accurately describe vapor-liquid curves for alkanes and alkenes. As it has been successively tested in GCMC simulations of adsorption of hydrocarbons for a wide range of zeolites and MOFs, ${ }^{49-52}$ we do not anticipate our choice of force field to be the source of significant differences between calculated and measured uptakes. We therefore attribute such differences to the nonrealistic, ideal structure of the Zr-fumarate-MOF used in the first set of GCMC calculations. However, the simulated isotherms qualitatively agree with the measured ones (preference of propane in lower pressures and propylene in higher). We can relate it to two properties of the analyzed molecules-(i) the heat of adsorption of propane $(42.7 \mathrm{~kJ}$ $\mathrm{mol}^{-1}$ with GCMC and $44 \mathrm{~kJ} \mathrm{~mol}^{-1}$ in calorimetry) is slightly

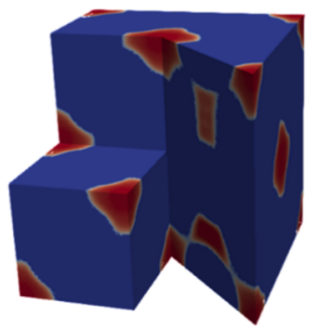

Perfect

propane

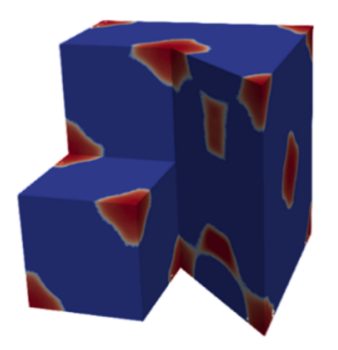

Perfect

propylene

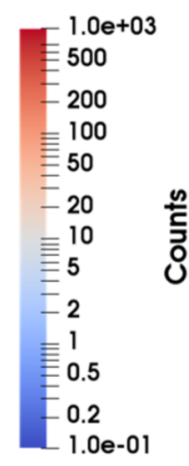

오ํ

Positive amplitude

c

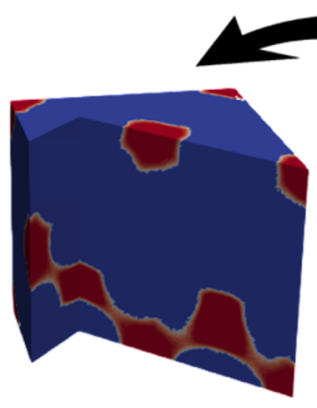

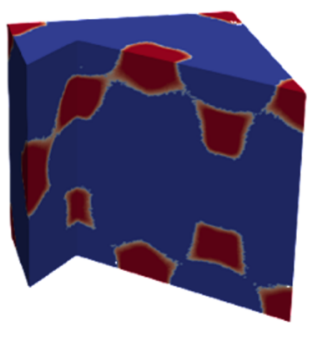

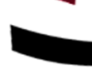

Negative amplitude

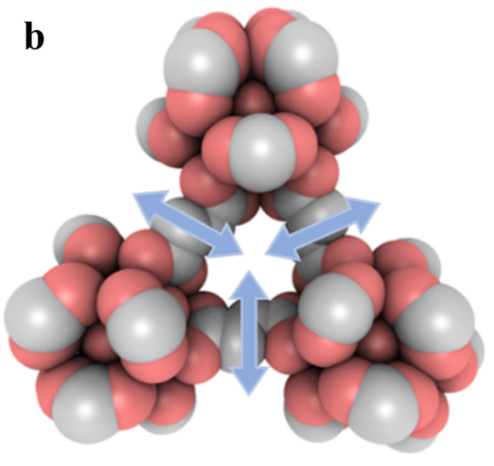

d

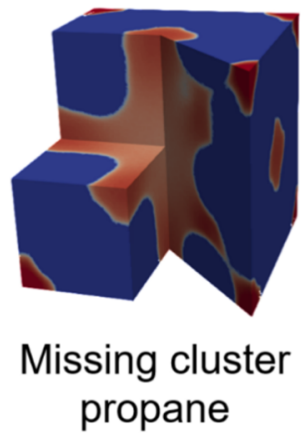

Figure 4. (a) Density maps for propane and propylene adsorption in an ideal structure of Zr-fumarate-MOF. The propylene density map (right) is seen to be nearly identical to propane (left). A logarithmic scale is used for density visualization. (b) Trampoline-like mode related to gateenlargement. (c) Density maps for structure deformed according to the trampoline-like phonon. (d) Density map for adsorption in a missing cluster. 

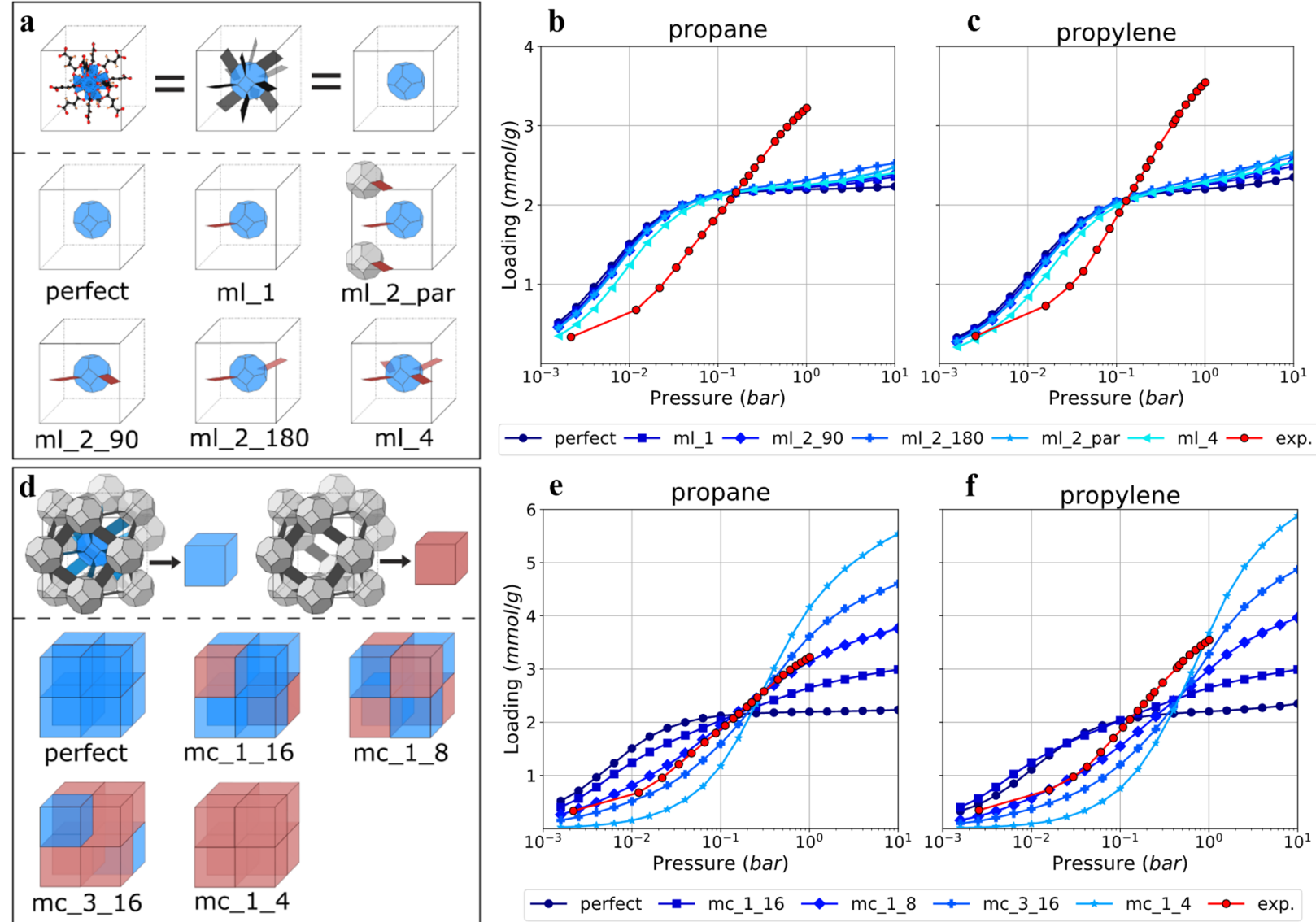

Figure 5. Depiction of assessed defect types: (a) missing-linker-type defects and (d) missing-cluster-type defects and corresponding supercells. Uptake of propane in Zr-fumarate-MOF with missing-linker-type defects (b) and with missing-cluster-type defects (e). Uptake of propylene in Zrfumarate-MOF with missing-linker-type defects (c) and with missing-cluster-type defects (f).

higher than that for propylene $\left(39.7 \mathrm{~kJ} \mathrm{~mol}^{-1}\right.$ with GCMC and $38 \mathrm{~kJ} \mathrm{~mol}^{-1}$ in calorimetry) which promotes the initial uptake of alkane and (ii) aforementioned diameters of molecules (0.43 $\mathrm{nm}$ for propane and $0.4 \mathrm{~nm}$ for propylene)-smaller molecules are simply packed in the pore with higher density.

To examine the distribution of molecules in the material pores, we calculated density maps. Figure 4a presents two cross sections of such maps, for propane and propylene. It can be seen that there are areas with finite values of density surrounded by the large areas (blue on Figure 4a) where adsorbate density is zero, or inaccessible regions for insertion. Several regions exist where the pockets of density are thinly (or nearly) connected, corresponding to the pore windows. These results indicate that diffusion between the gates in the perfect structure is unlikely to occur, which is contradictory to what has been measured experimentally. ${ }^{45}$ One possible explanation for the hydrocarbon uptake can be the presence of a vibrationally induced gate opening effect, as has been observed in MOFs such as ZIF-4, ZIF-7, and ZIF-8. ${ }^{53}$ To check how the flexibility of the framework affects the sizes of the gates, phonon calculations were performed (details of the methodology can be found in the Supporting Information). For our analysis, we selected modes of low frequency $\left(<130 \mathrm{~cm}^{-1}\right)$, since, as previously suggested, they may reflect potential adsorption-induced deformations of the framework. ${ }^{53,54} \mathrm{We}$ distinguished two separate collections of modes, $0-83$ and 92-129 $\mathrm{cm}^{-1}$, which correspond to rotation and translation of the metallic cluster and vibrations of the fumarate linkers, respectively. To ascertain whether some of those modes can be related to enlargement of the gate connecting two neighboring cages, we have generated structural snapshots of the material according to the deformation indicated by a particular mode with an arbitrary amplitude (positive and negative, CIF files available as Supporting Information). We then calculated the pore limiting diameter (PLD) using Poreblazer ${ }^{55}$ and selected the modes which increase this value (see Figure S13). For 10 modes which show the largest increase of the PLD, we calculated density maps, to check if the proposed deformations can connect the cages within the material. Resulting isosurfaces are presented in Figure S14. In particular, the mode located at $115.1 \mathrm{~cm}^{-1}$, which can be described by a trampoline-like motion of the linkers (Figure 4b), appears to be a good candidate for a gate-enlargement process. Calculated density distributions (Figure 4c) show that diffusion in the material deformed according to this particular phonon is possible and can explain the experimentally observed results of Liu et al. ${ }^{45}$

While vibrational modes can favor adsorbate diffusion in the pristine material, they do not shed light on the differences in adsorption kinetics, or the larger capacity than theoretically predicted. We must therefore examine the possibility of structural defect contribution. Indeed, a density map calculated for a unit cell with a missing cluster (Figure 4d) shows unobstructed communication between structural voids and may hold clues as to why the material used in this study readily adsorbs both probes. An in-depth look at the contribution of defects takes place in the next section. 
Evidence for Defects. A peculiar characteristic of the Zrfumarate-MOF is that, as reported in the original synthesis methodology, no crystalline material can be formed without the addition of a modulator, with excess formic acid improving the crystallinity of the obtained powder. This approach is wellknown to promote defect generation in the UiO-66 framework, with higher amounts of modulator leading to increased defect concentration, $^{56}$ and can be expected to extend to its isoreticular analogues. It has been previously shown that structural defects can drastically alter adsorption behavior and are commonly found in the high connectivity networks of multicoordinated zirconium cluster MOFs. ${ }^{57-59}$ Indeed, experiments investigating the $\mathrm{Zr}$-fumarate-MOF for the separation of butane isomers ${ }^{60}$ have found that iso-butane uptake becomes non-negligible when the MOF is synthesized with a large modulator excess. As iso-butane molecules are too large to pass through the cage windows, the presence of additional porosity or cage widening can explain such results.

It is therefore reasonable to assume that the presence of structural defects in the $\mathrm{Zr}$-fumarate-MOF may account for the observed discrepancy between experimental and modeled isotherms. The decreasing enthalpy profiles equally suggest some form of energetic heterogeneity. Choi and co-workers ${ }^{44}$ have interpreted the low relative pressure at which water condenses in the small pores as a guest collaborative effect resulting from the presence of missing-linker defects. With this in mind, five model structures were designed in identical configurations, as reported by Choi et al., herein referred to as ml_1, ml_2_90, ml_2_180, ml_2_par, and ml_4 (CIF files available as Supporting Information). The prefix stands for missing linker, followed by the number and, where applicable, the relative positions where linkers were removed (see Figure 5a). For charge compensation, missing linkers were substituted by two formic acid capping molecules, as this is the modulator available during synthesis and it is expected to remain coordinated to the metal sites. ${ }^{58}$ Figure 5 shows the simulated adsorption isotherms of propane (b) and propylene (c) for the missing-linker structures. Regardless of their distribution, the introduction of missing-linker defects did not change the characteristics of the simulated isotherms, leading only to a slight increase in uptake for pressures approaching 10 bar. Due to the small size of the fumarate linker compared to other isoreticular analogues, its removal and subsequent formate capping do not generate a significantly larger void space in the structure.

Alternative types of structural imperfections include missingcluster-type defects. It has been reported that this type of structural deviation from the ideal structure leads to decreased adsorption in the low-pressure region, followed by an increase in the uptake at higher pressures, ${ }^{61}$ and may explain the experimental results. In order to test this hypothesis, a new framework model was constructed, considering a missingcluster defect. Assembly of the new model consisted of the removal of an entire inorganic cluster, together with the connecting linkers and subsequent capping of open metal sites in adjoining clusters with formate ions. We artificially introduced several such configurations in a $2 \times 2 \times 2$ supercell, with no adjoining defects-with $1 / 4,3 / 16,1 / 8$, and $1 / 16$ of the total number of clusters removed (as shown in Figure 5d) and further referred to as mc_1_4, mc_3_16, $\mathrm{mc} 1$ 1_8, and $\mathrm{mc} 11$ 16 $(\mathrm{mc}=$ missing cluster $)$. The resulting $\mathrm{CIF}$ files are available as Supporting Information. Figure 5e,f shows the calculated isotherms for the aforementioned structures and confirms that the absence of metallic clusters in the structure of the $\mathrm{Zr}$-fumarate-MOF is responsible for the observed shift of the pore-filling step and higher total capacity in the experimental results. In addition, quantitative conclusions can be drawn-we see that the isotherm predicted by mc_1_8 (1/8 missing total clusters $)$ is the best fit to the measured isotherm-practically a full overlap for propane and a slight underestimate for propylene at higher pressures. It is worth highlighting that these isotherms are calculated in a periodic supercell, introducing artificial long-range periodicity of defects, possibly unrepresentative of the real sample. The results are interpreted in a statistical manner such that a structure with a particular concentration of defects can be a possible candidate to describe experimentally observed adsorption.

Physical evidence for structural defects may be obtained from characterization techniques such as TGA, ${ }^{1} \mathrm{H}$ NMR, and high resolution XRD. The thermogravimetric curve can be used to gauge the percentage of missing-linker defects in the structure (as has been previously reported ${ }^{62}$ ) by stoichiometrically calculating the weight ratio at $550 \mathrm{~K}$ (where it is assumed that any adsorbed water, residual solvent, and defect site cappers have been removed) to the inorganic residue after combustion in the oxygen-rich atmosphere at $937 \mathrm{~K}$ (corresponding to $\mathrm{ZrO}_{2}$ ). The resulting cluster-to-linker ratio for the $\mathrm{Zr}$-fumarate-MOF sample is found to be around 5. This organic to inorganic balance, below the ideal value 6 for the defect-free MOF, confirms the presence of structural defects in the experimental sample. Unfortunately, the thermogravimetric method cannot differentiate between missing-linker-type and missing-cluster-type defects. If assuming only missing-clustertype defects are present, their concentration can be calculated as $1 / 7$, remarkably close to the simulated best-fitting ratio of $1 / 8$.

To further shed light on the nature of the underlined structural defects, solution ${ }^{1} \mathrm{H}$ NMR was performed on a $\mathrm{NaOD}$ digested sample. The resulting spectrum (Figure 6) reveals the presence of three distinct and well resolved singlet peaks attributed to water $(4.79 \mathrm{ppm})$, fumarate $(6.23 \mathrm{ppm})$, and formate $(8.17 \mathrm{ppm})$. The observed water signal demonstrates its presence in the structure and can be attributed to several sources: (i) an adsorbed phase in the pores or (ii) defect sites which are capped by water molecules or hydroxide groups instead of formate groups. This structural $\mathrm{H}_{2} \mathrm{O}$ can be traced either to the initial synthesis or through latter adsorption due to the high $\mathrm{Zr}$-fumarate-MOF affinity for atmospheric water. As water capping is energetically favored ${ }^{63}$ but cannot be deconvoluted from the adsorbed phase, we will only consider the ratio of carboxylates, with the mention that more defect sites than calculated are likely to exist in the sample. Based on the normalized integrated areas of the fumarate and formate signals and under the assumption that these are the only structural elements of the framework, we determine that the components are present in a proportion of 15:1 for fumarate and formate, respectively. Given this ratio and further considering missing-cluster defects as the only type present, we estimate that for every three perfect unit cells a fourth unit cell with a missing-cluster defect exists, or $1 / 16$ missing clusters. This ratio, lower than that determined through TGA or GCMC, points to the existence of water capped defect sites alongside formate.

Neither TGA nor ${ }^{1} \mathrm{H}$ NMR can differentiate between missing-linker and missing-cluster defects, so no prediction of 


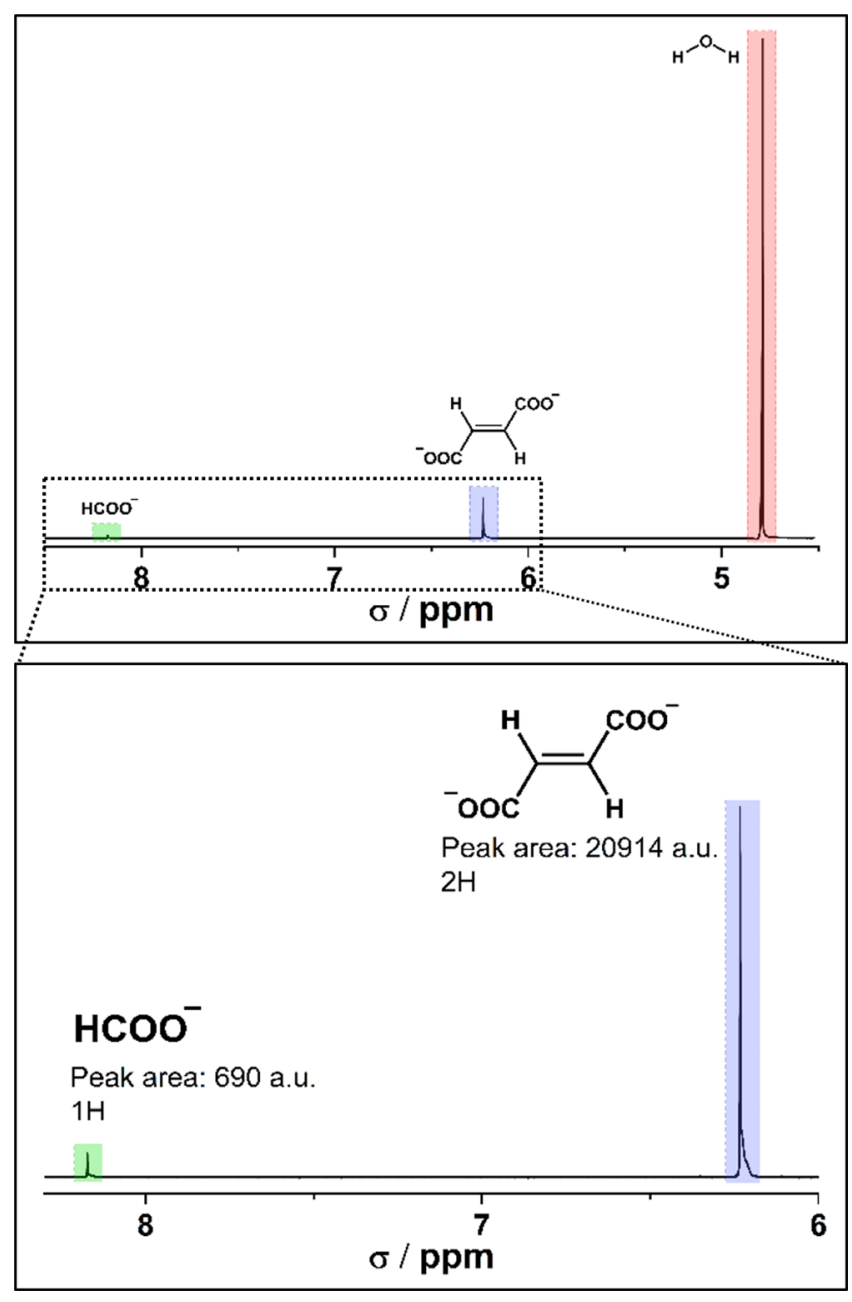

Figure 6. ${ }^{1} \mathrm{H}$ NMR of $\mathrm{Zr}$-fumarate-MOF with highlighted 9-6 region and integrated peaks for formate and fumarate in green and blue, respectively. The peak corresponding to water is displayed in red.

selective preponderance in the structure can be made. However, if the predicted missing-cluster defects are present in a correlated fashion, clues may arise in the PXRD pattern. The reo phase has been demonstrated to cluster defects in correlated nanodomains during synthesis for the sibling $\mathrm{UiO}$ 66 when prepared under formic acid-rich conditions, giving rise to symmetry forbidden signals in the low $2 \theta$ range. ${ }^{62,64-66}$ The presence of these reflections can therefore be employed as a benchmark for the occurrence of the secondary phase with lower cluster content. Indeed, a second high-resolution capillary XRD characterization of the activated framework reveals the characteristic profile of Zr-fumarate-MOF (blue in Figure 7) accompanied by low intensity signals, supporting the existence of missing-cluster defects in conformity with previous reports on isoreticular $\mathrm{Zr}$ MOFs. The experimental pattern did not display the typical reo phase (100) and (110) plane reflections but a broad diffuse scattering signal in the low angle region $\left(2.3-7.6^{\circ}\right)$, leading us to hypothesize the presence of a low amount of highly dispersed missing clusters arranged in a noncorrelated fashion. Careful examination of the sample's diffractogram reveals the presence of well-defined, low intensity reflections indexed exclusively to the missing-cluster structure (black arrows in Figure 7) for $2 \theta$ angles greater than $16^{\circ}$, suggesting the presence of missing-cluster defects with short-range ordering or correlation. We can therefore

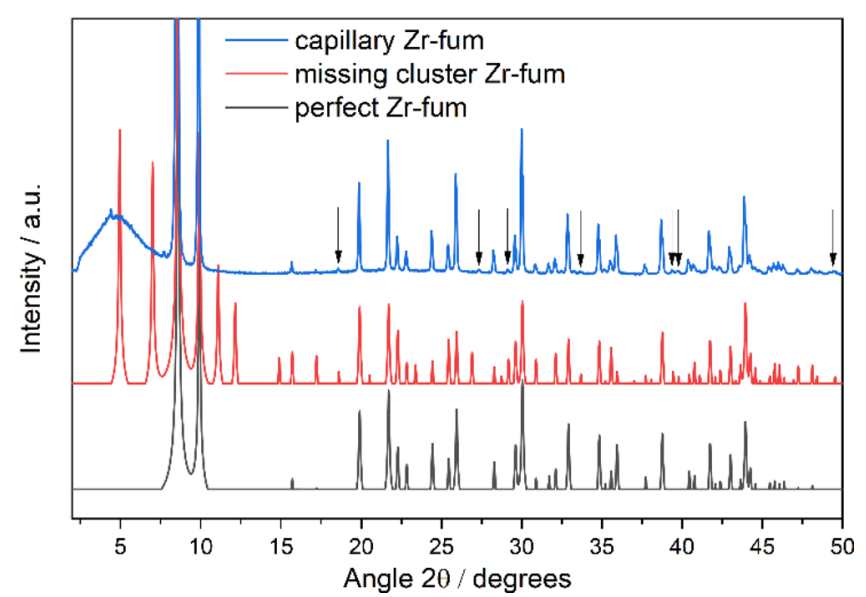

Figure 7. Capilary XRD of the Zr-fumarate-MOF sample (blue) with simulated patterns of the fcu (black) and reo (red) phases.

conclude, with a high degree of certainty, that the sample in question does in fact carry missing-cluster defects responsible for the formation of a distinct defective reo phase. However, it is present in minor abundance compared to the regular fcu phase.

A parallel can be made with the smallest currently known analogue of the UiO-66 isoreticular series, zirconium squarate (ZrSQU) synthesized by Bueken et al. ${ }^{67}$ In $\mathrm{ZrSQU}$, the crystal structure predicts no possible adsorption of even smaller molecules, such as nitrogen. The presence of what the authors suggest to be missing-linker defects leads to an accessible porosity in $\mathrm{N}_{2}$ physisorption (although no computational study of the diffusion of nitrogen into the proposed defective structure was made). It is however likely that, in a system which is even more confined than the Zr-fumarate-MOF, a larger preponderance of missing-cluster defects can be present, as suggested by the broad reflections at low angles of the PXRD pattern in the original publication indicative of a mixed phase framework with coexistence of fcu and reo forms.

Separation of Propane-Propylene Mixtures. To evaluate the material for thermodynamic propane-propylene separation, simulations of equimolar mixture adsorption were performed in previously mentioned structures. The simulated selectivity $(\alpha)$ of the ideal structure, $\mathrm{ml} \_1, \mathrm{ml} \_4, \mathrm{mc} \_1 \_8$, and mc_1_4, is shown in Figure 8a, while the rest can be found in the Supporting Information (Figure S15). It should be noted that the values in Figure 8a are obtained with the assumption of equilibrium and complete adsorbate access to the entire porous network. It is to be expected that, in the pristine structure, apparent selectivity would be dependent on diffusion and size exclusion. Selectivity can be seen to be above unity for propane and decrease with higher total mixture pressure, even with the presence of defects. Starting from pure component isotherms, ideal adsorbed solution theory (IAST) can also forecast multicomponent adsorption selectivity at different pressures. The calculated selectivity curve, shown in Figure S10, predicts a slightly lower selectivity than what is obtained through coadsorption simulations with a $\alpha$ value of around 1.3 for propane at 0.2 bar total pressure, also decreasing with higher pressures.

As previously mentioned, both simulated coadsorption and IAST predictions assume thermodynamic equilibrium between the gaseous and adsorbed phases. No difference in equilibrium time was observed in pure component adsorption (Figure S9). 

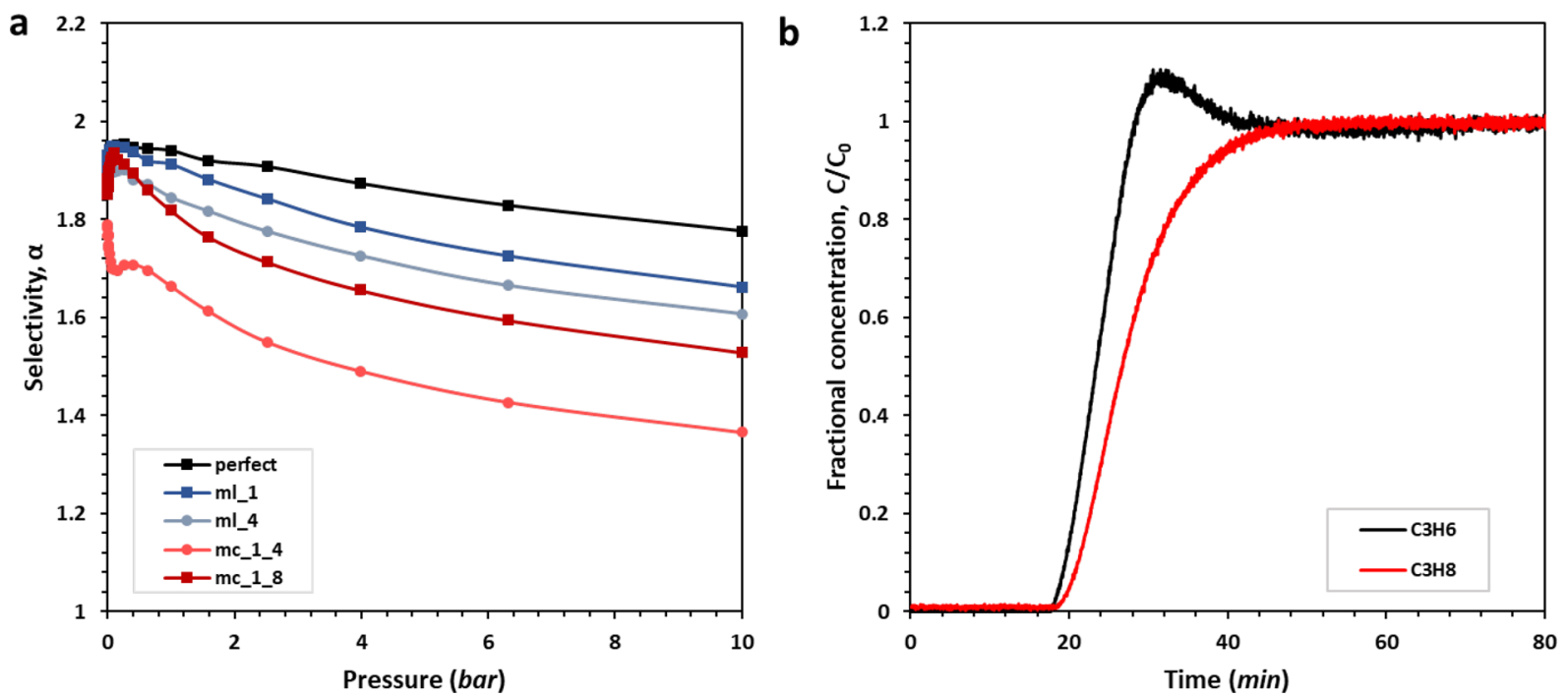

Figure 8. (a) Simulated selectivity of a 1:1 molar mixture of propane and propylene at various total mixture pressures. Black, blue, and red represent pristine, missing-linker, and missing-cluster structures, respectively. (b) Breakthrough curves of an equimolar propane-propylene mixture in carrier gas at a total inlet pressure of 1 bar. Propane is in red and propylene in black.

To further evaluate the impact of possible kinetic or size exclusion effects, breakthrough adsorption experiments were carried out with a $\mathrm{C}_{3} \mathrm{H}_{6}: \mathrm{C}_{3} \mathrm{H}_{6}: \mathrm{Ar}=5: 5: 90$ gas mixture at $295 \mathrm{~K}$ and $1 \mathrm{bar} / 5$ bar total pressure. Argon was chosen as the carrier gas due to its inert nature and negligible uptake when compared to the hydrocarbons. The breakthrough curves recorded at 1 bar (Figure $8 \mathrm{~b}$ ) show the material indeed adsorbs propane over propene and that the selectivity (as calculated through eq 2 in the Supporting Information) is 1.28, remarkably consistent with the IAST prediction. At breakthrough, the capacities for propane and propene are 1.63 and $1.268 \mathrm{mmol} \mathrm{g}^{-1}$, respectively. Breakthrough curves recorded at 5 bar total pressure (Figure S12) show an expected decrease in selectivity for propane.

The column breakthrough experiment rules out any significant molecular sieving or kinetic separation in this $\mathrm{Zr}$ fumarate-MOF sample. However, $\mathrm{Zr}$-fumarate-MOF was recently used to create a mixed-matrix membrane which was shown to have an improved selectivity for propylene (approximately 10), above the theoretical upper bound of a pure polymer membrane. ${ }^{45}$ The authors attribute the result to a conformation-controlled sieving effect which allows for faster diffusion of propylene through the crystal. The marked difference between the adsorption behavior of the two samples can be explained by the additional porosity introduced by the presence of missing-cluster defects. This would increase the diffusion rates of both probes inside the crystal and allow for communication between different pores through the resulting channels. This pore network can explain the relatively fast kinetics of adsorption observed with both propane and propylene in our sample, in contrast to what is likely to be a more "perfect" material.

When comparing the performance of defective $\mathrm{Zr}$-fumarateMOF with other adsorbents, propane selectivity is rarely observed. Several studies also highlight a slight thermodynamic preference for paraffins over olefins in adsorbents such as AlMePO- $\alpha,{ }^{19}$ IRMOF- $8,{ }^{68}$ and MIL-53(Al)-FA. ${ }^{69}$ In these cases, as with $\mathrm{Zr}$-fumarate-MOF, the preference for propane is attributed to stronger nonspecific interactions with the structure. However, Zr-fumarate-MOF is, to the best of our knowledge, the first adsorbent which can be switched between kinetic selectivity for propylene and thermodynamic selectivity for propane through defect engineering.

\section{CONCLUSIONS}

In this study, the adsorption of saturated and monounsaturated C3 hydrocarbons on a sample of $\mathrm{Zr}$-fumarate-MOF synthesized with a large excess of formic acid modulator was studied through a combined experimental and simulation methodology. Anomalous results highlighted through microcalorimetry screening and experimental isotherms were explained on the basis of material defects. Two types of defects-missing linker and missing cluster-in various concentrations and conformations in the material structure have been simulated. It was found that missing-linker defects have little effect on the equilibrium adsorption behavior of $\mathrm{C} 3$ hydrocarbons and that the experimental isotherms can best be described by a model where $1 / 8$ of the total zirconium clusters are missing.

We have also shown that the phonon vibrational modes can favor adsorbate diffusion in the pristine material. Logically, they must also have an influence on adsorption in the defective structure, especially when the pore aperture is comparable with the kinetic diameter of the adsorbate. In such a case, dynamic deformations of low frequency phonons will substantially facilitate adsorption.

Surprisingly, mixture coadsorption GCMC simulations and IAST predictions on the material suggest a preference for propane over propylene adsorption, contrary to what can be expected on a pristine structure. ${ }^{45}$ Column breakthrough experiments corroborate this effect, with resulting breakthrough curves suggesting relatively fast kinetics for both probes. Therefore, it is logical to postulate that the presence of structural defects can drastically affect the separation of the C3 mixture and may ultimately be employed as an avenue for tuning separation performance.

Overall, this work furthers the understanding of the role of defects in Zr-fumarate-MOF (or MOF-801). In this case, the introduction of defects led to an unexpected change in selectivity from propylene to propane. Although the separation factor is too low for practical applications, this behavior opens 
the door to the possibility of materials which allow for the recovery of propylene in the raffinate stream, a property highly desirable in PSA/TSA separation processes. Our work shows that the selectivity of MOFs in separation processes can in principle be controlled using their defect chemistry, posing the challenge to further develop the methods of defect engineering.

\section{MATERIALS AND METHODS}

Details pertaining to the synthesis of the $\mathrm{Zr}$-fumarate-MOF, its characterization, and the computational modeling can be found in the Supporting Information.

\section{ASSOCIATED CONTENT}

\section{S Supporting Information}

The Supporting Information is available free of charge on the ACS Publications website at DOI: 10.1021/acs.chemmater.9b02322.

Details regarding material synthesis, SEM images of resulting crystals, supplementary PXRD patterns, ${ }^{1} \mathrm{H}$ NMR methodology, thermogravimetry curves, adsorption methodology and isotherms for nitrogen at $77 \mathrm{~K}$, water at $289 \mathrm{~K}$, and propane/propylene at $303 \mathrm{~K}$, complete microcalorimetry results for all probes, adsorption kinetics, IAST coadsorption predictions, methodology for column breakthrough experiments, as well as details about DFT and GCMC computational methods (PDF)

An archive with CIF files of all DFT-optimized structures-ideal, linker defective, and cluster defective supercells - used in this study (ZIP)

\section{AUTHOR INFORMATION}

\section{Corresponding Author}

*E-mail: philip.llewellyn@univ-amu.fr.

\section{ORCID ${ }^{\circ}$}

Paul Iacomi: 0000-0001-5477-1503

Joao Marreiros: 0000-0002-4898-2096

Jin Shang: 0000-0001-5165-0466

Rob Ameloot: 0000-0003-3178-5480

Bogdan Kuchta: 0000-0002-8635-4154

Philip L. Llewellyn: 0000-0001-5124-7052

\section{Author Contributions}

$\nabla$ P.I., F.F.: Contributed equally to this work.

\section{Notes}

The authors declare no competing financial interest.

\section{ACKNOWLEDGMENTS}

P.I., P.L.L., J.M., and R.A. have received funding from the European Union's Horizon 2020 research and innovation programme under the Marie Sklodowska-Curie Grant Agreement No. 641887 (project acronym: DEFNET). F.F., J.R., and B.K. are supported by the Polish National Science Centre (NCN, Grant No. 2015/17/B/ST8/00099). J.S. acknowledges the financial support from the Research Grants Council of Hong Kong (CityU 21301817). This research was supported in part by PL-Grid Infrastructure. F.F. thanks Dr. Halina Maniak for insightful discussions on coordinational chemistry.

\section{REFERENCES}

(1) McSpadden, P.; Dina, T.; Lewandowski, S.; Cui, T.; Marinelli, J.; Ali, A. North America Propylene Supply Study; IHS Markit, 2018; ihsmarkit.com/products/north-america-propylene-supply.html [Online; accessed Jan 26, 2019].

(2) Eldridge, R. B. Olefin/Paraffin Separation Technology: A Review. Ind. Eng. Chem. Res. 1993, 32, 2208-2212.

(3) Jarvelin, H.; Fair, J. R. Adsorptive Separation of PropylenePropane Mixtures. Ind. Eng. Chem. Res. 1993, 32, 2201-2207.

(4) Hybrid Separations/Distillation Technology: Research Opportunities for Energy and Emissions Reduction; USA Department of Energy, 2005; www.energy.gov/sites/prod/files/2013/11/f4/hybrid_separation.pdf [Online; accessed Sept 3, 2018].

(5) Shimazu, A.; Miyazaki, T.; Maeda, M.; Ikeda, K. Relationships between the Chemical Structures and the Solubility, Diffusivity, and Permselectivity of Propylene and Propane in 6FDA-Based Polyimides. J. Polym. Sci., Part B: Polym. Phys. 2000, 38, 2525-2536.

(6) Ilinitch, O.; Semin, G.; Chertova, M.; Zamaraev, K. Novel Polymeric Membranes for Separation of Hydrocarbons. J. Membr. Sci. 1992, 66, 1-8.

(7) Tanaka, K.; Taguchi, A.; Hao, J.; Kita, H.; Okamoto, K. Permeation and Separation Properties of Polyimide Membranes to Olefins and Paraffins. J. Membr. Sci. 1996, 121, 197-207.

(8) Glanz, P.; Findenegg, G. H. Adsorption of Gas Mixtures of Propene and Propane on Graphitized Carbon Black I. Experimental Method and Results. Adsorpt. Sci. Technol. 1984, 1, 41-50.

(9) Liu, J.; Liu, Y.; Kayrak Talay, D.; Calverley, E.; Brayden, M.; Martinez, M. A. New Carbon Molecular Sieve for Propylene/Propane Separations. Carbon 2015, 85, 201-211.

(10) Glanz, P.; Körner, B.; Findenegg, G. H. Adsorption of Propene and Propane on Graphitized Carbon. II. Analysis of Single Gas and Mixed Gas Isotherms. Adsorpt. Sci. Technol. 1984, 1, 183-193.

(11) Shu, C.; Kulvaranon, S.; Findley, M.; Liapis, A. Experimental and Computational Studies on Propane-Propylene Separation by Adsorption and Variable-Temperature Stepwise Desorption. Sep. Technol. 1990, 1, 18-28.

(12) Schoellner, R.; Mueller, U. Influence of Mono- and Bivalent Cations in 4A-Zeolites on the Adsorptive Separation of Ethene and Propene from Crack-Gases. Adsorpt. Sci. Technol. 1986, 3, 167-171.

(13) Combariza, A. F.; Sastre, G.; Corma, A. Propane/Propylene Diffusion in Zeolites: Framework Dynamics. J. Phys. Chem. C 2009, 113, 11246-11253.

(14) Grande, C. A.; Gigola, C.; Rodrigues, A. E. Adsorption of Propane and Propylene in Pellets and Crystals of 5A Zeolite. Ind. Eng. Chem. Res. 2002, 41, 85-92.

(15) Selzer, C.; Werner, A.; Kaskel, S. Selective Adsorption of Propene over Propane on Hierarchical Zeolite ZSM-58. Ind. Eng. Chem. Res. 2018, 57, 6609-6617.

(16) Khalighi, M.; Chen, Y. F.; Farooq, S.; Karimi, I. A.; Jiang, J. W. Propylene/Propane Separation Using SiCHA. Ind. Eng. Chem. Res. 2013, 52, 3877-3892.

(17) Grande, C. A.; Araujo, J. D. P.; Cavenati, S.; Firpo, N.; Basaldella, E.; Rodrigues, A. E. New $\pi$-Complexation Adsorbents for Propane-Propylene Separation. Langmuir 2004, 20, 5291-5297.

(18) Safarik, D. J.; Eldridge, R. B. Olefin/Paraffin Separations by Reactive Absorption: A Review. Ind. Eng. Chem. Res. 1998, 37, 25712581.

(19) Kroon, M. C.; Vega, L. F. Selective Paraffin Removal from Ethane/Ethylene Mixtures by Adsorption into Aluminum Methylphosphonate- $\alpha$ : A Molecular Simulation Study. Langmuir 2009, 25, $2148-2152$.

(20) Koros, W. J.; Mahajan, R. Pushing the Limits on Possibilities for Large Scale Gas Separation: Which Strategies? J. Membr. Sci. 2000, $175,181-196$.

(21) Ruthven, D. M. Principles of Adsorption and Adsorption Processes; Wiley: New York, 1984.

(22) Zhu, W.; Kapteijn, F.; Moulijn, J. A.; den Exter, M. C.; Jansen, J. C. Shape Selectivity in Adsorption on the All-Silica DD3R. Langmuir 2000, 16, 3322-3329.

(23) Olson, D. H.; Camblor, M. A.; Villaescusa, L. A.; Kuehl, G. H. Light Hydrocarbon Sorption Properties of Pure Silica Si-CHA and 
ITQ-3 and High Silica ZSM-58. Microporous Mesoporous Mater. 2004, 67, 27-33.

(24) Gascon, J.; Blom, W.; van Miltenburg, A.; Ferreira, A.; Berger, R.; Kapteijn, F. Accelerated Synthesis of All-Silica DD3R and Its Performance in the Separation of Propylene/Propane Mixtures. Microporous Mesoporous Mater. 2008, 115, 585-593.

(25) Rubeš, M.; Wiersum, A. D.; Llewellyn, P. L.; Grajciar, L.; Bludský, O.; Nachtigall, P.; Rubes, M.; Wiersum, A. D.; Llewellyn, P. L.; Grajciar, L.; Bludský, O.; Nachtigall, P. Adsorption of Propane and Propylene on CuBTC Metal-Organic Framework: Combined Theoretical and Experimental Investigation. J. Phys. Chem. C 2013, 117, 11159-11167.

(26) Plaza, M.; Ribeiro, A.; Ferreira, A.; Santos, J.; Lee, U.-H.; Chang, J.-S.; Loureiro, J.; Rodrigues, A. Propylene/Propane Separation by Vacuum Swing Adsorption Using Cu-BTC Spheres. Sep. Purif. Technol. 2012, 90, 109-119.

(27) Yoon, J. W.; et al. Controlled Reducibility of a Metal-Organic Framework with Coordinatively Unsaturated Sites for Preferential Gas Sorption. Angew. Chem., Int. Ed. 2010, 49, 5949-5952.

(28) Autie-Castro, G.; Autie, M.; Reguera, E.; Moreno-Tost, R.; Rodríguez-Castellón, E.; Jiménez-López, A.; Santamaría-González, J. Adsorption and Separation of Propane and Propylene by Porous Hexacyanometallates. Appl. Surf. Sci. 2011, 257, 2461-2466.

(29) Lee, C. Y.; Bae, Y.-S.; Jeong, N. C.; Farha, O. K.; Sarjeant, A. A.; Stern, C. L.; Nickias, P.; Snurr, R. Q.; Hupp, J. T.; Nguyen, S. T. Kinetic Separation of Propene and Propane in Metal-Organic Frameworks: Controlling Diffusion Rates in Plate-Shaped Crystals via Tuning of Pore Apertures and Crystallite Aspect Ratios. J. Am. Chem. Soc. 2011, 133, 5228-5231.

(30) Assen, A. H.; Belmabkhout, Y.; Adil, K.; Bhatt, P. M.; Xue, D.X.; Jiang, H.; Eddaoudi, M. Ultra-Tuning of the Rare-Earth Fcu-MOF Aperture Size for Selective Molecular Exclusion of Branched Paraffins. Angew. Chem., Int. Ed. 2015, 54, 14353-14358.

(31) Pan, Y.; Li, T.; Lestari, G.; Lai, Z. Effective Separation of Propylene/Propane Binary Mixtures by ZIF-8 Membranes. J. Membr. Sci. 2012, 390-391, 93-98.

(32) Li, K.; Olson, D. H.; Seidel, J.; Emge, T. J.; Gong, H.; Zeng, H.; Li, J. Zeolitic Imidazolate Frameworks for Kinetic Separation of Propane and Propene. J. Am. Chem. Soc. 2009, 131, 10368-10369.

(33) Gücüyener, C.; van den Bergh, J.; Gascon, J.; Kapteijn, F. Ethane/Ethene Separation Turned on Its Head: Selective Ethane Adsorption on the Metal-Organic Framework ZIF-7 through a GateOpening Mechanism. J. Am. Chem. Soc. 2010, 132, 17704-17706.

(34) van den Bergh, J.; Gücüyener, C.; Pidko, E. A.; Hensen, E. J. M.; Gascon, J.; Kapteijn, F. Understanding the Anomalous Alkane Selectivity of ZIF-7 in the Separation of Light Alkane/Alkene Mixtures. Chem. - Eur. J. 2011, 17, 8832-8840.

(35) Fairen-Jimenez, D.; Moggach, S. A.; Wharmby, M. T.; Wright, P. A.; Parsons, S.; Düren, T. Opening the Gate: Framework Flexibility in ZIF-8 Explored by Experiments and Simulations. J. Am. Chem. Soc. 2011, 133, 8900-8902.

(36) Wißmann, G.; Schaate, A.; Lilienthal, S.; Bremer, I.; Schneider, A. M.; Behrens, P. Modulated Synthesis of Zr-Fumarate MOF. Microporous Mesoporous Mater. 2012, 152, 64-70.

(37) Furukawa, H.; Gándara, F.; Zhang, Y.-B.; Jiang, J.; Queen, W. L.; Hudson, M. R.; Yaghi, O. M. Water Adsorption in Porous MetalOrganic Frameworks and Related Materials. J. Am. Chem. Soc. 2014, 136, 4369-4381.

(38) Ren, J.; Musyoka, N. M.; Langmi, H. W.; North, B. C.; Mathe, M.; Pang, W.; Wang, M.; Walker, J. In-Situ IR Monitoring of the Formation of Zr-Fumarate MOF. Appl. Surf. Sci. 2017, 404, 263-267.

(39) Zahn, G.; Schulze, H. A.; Lippke, J.; König, S.; Sazama, U.; Fröba, M.; Behrens, P. A Water-Born Zr-Based Porous Coordination Polymer: Modulated Synthesis of Zr-Fumarate MOF. Microporous Mesoporous Mater. 2015, 203, 186-194.

(40) Reinsch, H.; Waitschat, S.; Chavan, S. M.; Lillerud, K. P.; Stock, N. A Facile "Green" Route for Scalable Batch Production and Continuous Synthesis of Zirconium MOFs: A Facile "Green” Route for Scalable Batch Production and Continuous Synthesis of Zirconium MOFs. Eur. J. Inorg. Chem. 2016, 2016, 4490-4498.

(41) Bueken, B.; Van Velthoven, N.; Willhammar, T.; Stassin, T.; Stassen, I.; Keen, D. A.; Baron, G. V.; Denayer, J. F. M.; Ameloot, R.; Bals, S.; De Vos, D.; Bennett, T. D. Gel-Based Morphological Design of Zirconium Metal-Organic Frameworks. Chemical Science 2017, 8, 3939-3948.

(42) Bae, Y. J.; Cho, E. S.; Qiu, F.; Sun, D. T.; Williams, T. E.; Urban, J. J.; Queen, W. L. Transparent Metal-Organic Framework/ Polymer Mixed Matrix Membranes as Water Vapor Barriers. ACS Appl. Mater. Interfaces 2016, 8, 10098-10103.

(43) Kim, H.; Yang, S.; Rao, S. R.; Narayanan, S.; Kapustin, E. A.; Furukawa, H.; Umans, A. S.; Yaghi, O. M.; Wang, E. N. Water Harvesting from Air with Metal-Organic Frameworks Powered by Natural Sunlight. Science 2017, 356, 430-434.

(44) Choi, J.; Lin, L.-C.; Grossman, J. C. Role of Structural Defects in the Water Adsorption Properties of MOF-801. J. Phys. Chem. C 2018, 122, 5545-5552.

(45) Liu, Y.; Chen, Z.; Liu, G.; Belmabkhout, Y.; Adil, K.; Eddaoudi, M.; Koros, W. Conformation-Controlled Molecular Sieving Effects for Membrane-Based Propylene/Propane Separation. Adv. Mater. 2019, 31, 1807513.

(46) Dubbeldam, D.; Calero, S.; Vlugt, T. J. iRASPA: GPUAccelerated Visualization Software for Materials Scientists. Mol. Simul. 2018, 44, 653-676.

(47) Zahn, G.; Zerner, P.; Lippke, J.; Kempf, F. L.; Lilienthal, S.; Schröder, C. A.; Schneider, A. M.; Behrens, P. Insight into the Mechanism of Modulated Syntheses: In Situ Synchrotron Diffraction Studies on the Formation of Zr-Fumarate MOF. CrystEngComm 2014, 16, 9198-9207.

(48) Liu, B.; Smit, B.; Rey, F.; Valencia, S.; Calero, S. A New United Atom Force Field for Adsorption of Alkenes in Zeolites. J. Phys. Chem. C 2008, 112, 2492-2498.

(49) Luna-Triguero, A.; Vicent-Luna, J. M.; Becker, T. M.; Vlugt, T. J. H.; Dubbeldam, D.; Gómez-Álvarez, P.; Calero, S. Effective Model for Olefin/Paraffin Separation Using (Co, Fe, Mn, Ni)-MOF-74. ChemistrySelect 2017, 2, 665-672.

(50) Luna-Triguero, A.; Vicent-Luna, J. M.; Gómez-Álvarez, P.; Calero, S. Olefin/Paraffin Separation in Open Metal Site Cu-BTC Metal-Organic Framework. J. Phys. Chem. C 2017, 121, 3126-3132. (51) Luna-Triguero, A.; Vicent-Luna, J. M.; Dubbeldam, D.; GómezÁlvarez, P.; Calero, S. Understanding and Exploiting Window Effects for Adsorption and Separations of Hydrocarbons. J. Phys. Chem. C 2015, 119, 19236-19243.

(52) Min, J. G.; Luna-Triguero, A.; Byun, Y.; Balestra, S. R. G.; Vicent-Luna, J. M.; Calero, S.; Hong, S. B.; Camblor, M. A. Stepped Propane Adsorption in Pure-Silica ITW Zeolite. Langmuir 2018, 34, 4774-4779.

(53) Ryder, M. R.; Civalleri, B.; Bennett, T. D.; Henke, S.; Rudić, S.; Cinque, G.; Fernandez-Alonso, F.; Tan, J.-C. Identifying the Role of Terahertz Vibrations in Metal-Organic Frameworks: From GateOpening Phenomenon to Shear-Driven Structural Destabilization. Phys. Rev. Lett. 2014, 113, 215502.

(54) Rogacka, J.; Formalik, F.; Triguero, A. L.; Firlej, L.; Kuchta, B.; Calero, S. Intermediate States Approach for Adsorption Studies in Flexible Metal-Organic Frameworks. Phys. Chem. Chem. Phys. 2019, 21, 3294-3303.

(55) Sarkisov, L.; Harrison, A. Computational Structure Characterisation Tools in Application to Ordered and Disordered Porous Materials. Mol. Simul. 2011, 37, 1248-1257.

(56) Vermoortele, F.; Bueken, B.; Le Bars, G.; Van de Voorde, B.; Vandichel, M.; Houthoofd, K.; Vimont, A.; Daturi, M.; Waroquier, M.; Van Speybroeck, V.; Kirschhock, C.; De Vos, D. E. Synthesis Modulation as a Tool To Increase the Catalytic Activity of MetalOrganic Frameworks: The Unique Case of UiO-66(Zr). J. Am. Chem. Soc. 2013, 135, 11465-11468.

(57) Ghosh, P.; Colón, Y. J.; Snurr, R. Q. Water Adsorption in UiO66: The Importance of Defects. Chem. Commun. 2014, 50, 1132911331. 
(58) Gutov, O. V.; Hevia, M. G.; Escudero-Adán, E. C.; Shafir, A. Metal-Organic Framework (MOF) Defects under Control: Insights into the Missing Linker Sites and Their Implication in the Reactivity of Zirconium-Based Frameworks. Inorg. Chem. 2015, 54, 8396-8400.

(59) Trickett, C. A.; Gagnon, K. J.; Lee, S.; Gándara, F.; Bürgi, H.B.; Yaghi, O. M. Definitive Molecular Level Characterization of Defects in UiO-66 Crystals. Angew. Chem., Int. Ed. 2015, 54, 1116211167.

(60) Chen, Z.; Feng, L.; Liu, L.; Bhatt, P. M.; Adil, K.; Emwas, A.H.; Assen, A. H.; Belmabkhout, Y.; Han, Y.; Eddaoudi, M. Enhanced Separation of Butane Isomers via Defect Control in a Fumarate/ Zirconium-Based Metal Organic Framework. Langmuir 2018, 34, 14546-14551.

(61) Thornton, A. W.; Babarao, R.; Jain, A.; Trousselet, F.; Coudert, F.-X. Defects in Metal-Organic Frameworks: A Compromise between Adsorption and Stability? Dalton Trans. 2016, 45, 43524359.

(62) Shearer, G. C.; Chavan, S.; Bordiga, S.; Svelle, S.; Olsbye, U.; Lillerud, K. P. Defect Engineering: Tuning the Porosity and Composition of the Metal-Organic Framework UiO-66 via Modulated Synthesis. Chem. Mater. 2016, 28, 3749-3761.

(63) Marreiros, J.; Caratelli, C.; Hajek, J.; Krajnc, A.; Fleury, G.; Bueken, B.; De Vos, D. E.; Mali, G.; Roeffaers, M. B. J.; Van Speybroeck, V.; Ameloot, R. Active Role of Methanol in PostSynthetic Linker Exchange in the Metal-Organic Framework UiO-66. Chem. Mater. 2019, 31, 1359-1369.

(64) Cliffe, M. J.; Wan, W.; Zou, X.; a Chater, P.; Kleppe, A. K.; Tucker, M. G.; Wilhelm, H.; Funnell, N. P.; Coudert, F.-X.; Goodwin, A. L. Correlated Defect Nanoregions in a Metal-Organic Framework. Nat. Commun. 2014, 5, 4176.

(65) Shearer, G. C.; Chavan, S.; Ethiraj, J.; Vitillo, J. G.; Svelle, S.; Olsbye, U.; Lamberti, C.; Bordiga, S.; Lillerud, K. P. Tuned to Perfection: Ironing Out the Defects in Metal-Organic Framework UiO-66. Chem. Mater. 2014, 26, 4068-4071.

(66) Taddei, M.; Wakeham, R. J.; Koutsianos, A.; Andreoli, E.; Barron, A. R. Post-Synthetic Ligand Exchange in Zirconium-Based Metal-Organic Frameworks: Beware of the Defects! Angew. Chem., Int. Ed. 2018, 57, 11706-11710.

(67) Bueken, B.; Reinsch, H.; Reimer, N.; Stassen, I.; Vermoortele, F.; Ameloot, R.; Stock, N.; Kirschhock, C. E. A.; De Vos, D. A Zirconium Squarate Metal-Organic Framework with ModulatorDependent Molecular Sieving Properties. Chem. Commun. 2014, 50, 10055-10058.

(68) Pires, J.; Pinto, M. L.; Saini, V. K. Ethane Selective IRMOF-8 and Its Significance in Ethane-Ethylene Separation by Adsorption. ACS Appl. Mater. Interfaces 2014, 6, 12093-12099.

(69) Peng, J.; Sun, Y.; Wu, Y.; Lv, Z.; Li, Z. Selectively Trapping Ethane from Ethylene on Metal-Organic Framework MIL-53(Al)FA. Ind. Eng. Chem. Res. 2019, 58, 8290-8295. 